$$
\begin{array}{r}
\text { O APOCALI } \\
\text { DE BELO MOI } \\
\text { UMA CIDADE FRE } \\
\text { À CONSTRU } \\
\text { DA HIDRELÉTH }
\end{array}
$$




\section{O APOCALIPSE DE BELO MONTE: UMA CIDADE FRENTE À CONSTRUÇÃO DA HIDRELÉTRICA}

\section{GUTEMBERG ARMANDO DINIZ GUERRA}

UNIVERSIDADE FEDERAL do PARÁ

$$
\text { CÉSAR MARTINS DE SOUZA }{ }^{1}
$$




\title{
O APOCALIPSE DE BELO MONTE: UMA CIDADE FRENTE À CONSTRUÇÃO DA HIDRELÉTRICA
}

\section{Resumo}

Este texto reflete sobre os efeitos da construção da barragem de Belo Monte, visíveis nas ruas de Altamira, registrados em imagens fotográficas, evidenciados pelos discursos de seus moradores ou dos que exercem atividades profissionais e no comércio. Presentes em distintos momentos na cidade, acumularam-se notas e fotografias desde antes da implantação da barragem em 2009 até 2016, de maneira que além desse registro, aciona-se a memória dos pesquisadores, de diferentes atores e posicionamentos de atores sociais sobre Belo Monte para a elaboração deste texto. Conclui-se pela constatação do fim de um ciclo de ebulição e tumulto na vida social e econômica da cidade, para um momento de depressão, letargia, desaceleração, expectativa e desencanto provocados pela desmobilização dos recursos utilizados para este empreendimento.

Palavras chave: Grandes projetos, Amazônia, Hidrelétrica de Belo Monte, Altamira

\section{THE APOCALYPSE OF BELO MONTE: A CITY FACING THE CONSTRUCTION OF THE HYDROELECTRIC}

\begin{abstract}
This paper reflects on the effects of the construction of the Belo Monte dam, visible in the streets of Altamira, registered in photographic images, evidenced in the speeches of its residents or those who carry out professional activities and in commerce. Present at different moments in the city, notes and photographs were accumulated since before the dam was implemented in 2009 until 2016, so that in addition to this record, the memory of the researchers, of different actors and positions of social actors on Belo Monte is triggered for the elaboration of this paper. It is concluded by the finding of the end of a boiling cycle and turmoil in the social and economic life of the city, to a moment of depression, lethargy, deceleration, expectation and disenchantment caused by the demobilization of the resources used for this project.

Keywords: Large projects, Amazon, Belo Monte Hydroelectric, Altamira.
\end{abstract}




\section{EL APOCALIPSIS DE BELO MONTE: UNA CIUDAD FRENTE A LA CONSTRUCCIÓN DE LA HIDROELÉCTRICA}

\section{Resumen}

Este texto reflexiona sobre los efectos de la construcción de la barrera de Belo Monte, visibles en las calles de Altamira, que están registrados en imágenes fotográficas y se evidencian en los discursos de sus habitantes o de quienes ejercen actividades profesionales y de comercio. Para la elaboración de este texto, se acumularon notas y fotografías de la ciudad en distintos momentos, antes de la implantación de la barrera en 2009 hasta 2016. Además de ese registro, se accionaron las memorias de los investigadores, de diferentes actores, y los posicionamientos de actores sociales sobre Belo Monte. Se concluye constatando el final de un ciclo de ebullición y confusión en la vida social y económica de la ciudad, en tránsito hacia un momento de depresión, letargo, desaceleración, expectativa y desencanto, provocados por la desmovilización de los recursos utilizados para este emprendimiento.

Palabras Clave: Grandes proyectos, Amazonia, Hidroeléctrica de Belo Monte, Altamira

Gutemberg Armando Diniz Guerra

gguerra@ufpa.br

César Martins de Souza ${ }^{1}$

cesar@ufpa.br 


\section{O ANÚNCIO DO PROJETO E A RE- SISTÊNCIA ORIGINAL}

Permitimo-nos a associação com o apocalipse pela tensão existente entre dois tempos que se apresentam nos discursos e nas transformações ocorridas em Altamira no período de observações que fundamentam esse texto. Nessa associação, o fim dos tempos tanto pode ser interpretado pelas afirmações dos defensores da barragem de Belo Monte que anunciam uma nova era de prosperidade, seja pelo discurso enfático dos que se opõem à barragem e denunciam as incoerências, injustiças e agressões ao meio ambiente como sinais de que estaria na hora de uma intervenção metafísica para sanar tais mazelas. Embora assumindo a inspiração do estilo literário profético como define Duarte (1999:91), retiramos dessa aproximação o caráter religioso que possa ser evocado no que passamos a descrever.

O procedimento metodológico que nos permitiu a elaboração desse artigo foi o registro sistemático em cadernos de campo e nos arquivos eletrônicos, de fragmentos de falas colhidos em conversas nos diversos ambientes da cidade de Altamira durante o processo de execução da barragem, de 2009 a 2016. Fotografias foram feitas e armazenadas no computador, permitindo uma volta para comparar com o que de fato vinha sendo realizado. Esse material associado à memória dos autores, presentes durante todos os anos referidos, no cenário das transformações permitiram não só a descrição como a inferência sobre e a partir dos acontecimentos registrados.
Concebido e batizado como Kararaô, apropriando ou tentando se associar à identidade nativa marcada pela presença indígena representada pelos quatro troncos linguísticos mais representativos do país naquela região, o investimento na construção da hidrelétrica que se materializou sob a denominação de Belo Monte passou por diversas fases. A primeira e mais vigorosa reação partiu das comunidades indígenas que, em um encontro realizado em Altamira em 1989, ficou identificado pelo gesto de uma senhora, com um facão ameaçadoramente encostado no rosto de um alto funcionário da Eletronorte.

Este momento marcou a história da construção da hidrelétrica e foi amplamente noticiado em todo o país, por veículos de comunicação de circulação nacional, como a revista $V_{e j a}(\mathrm{O}$ aviso dos caiapós, 1989). O projeto que visava implementar cinco grandes barragens no rio Xingu foi planejado, segundo o Bispo da Prelazia do Xingu, D. Erwin Krautler, em 1975, logo após a construção da Transamazônica, e caminhava para sua concretização, em 1989, quando enfrentou forte resistência das populações indígenas, movimentos sociais e organismos internacionais. Krautler, na abertura do livro Tenotã-Mõ, expressa suas memórias sobre os embates em torno da construção da hidrelétrica, com destaque para o I Encontro dos Povos Indígenas do Xingu, em 1989:

"O evento que reunia em torno de 600 índios, pintados para a guerra, teve enorme repercussão em todo o Brasil e no exterior. A foto que retratou a cena em que a índia Tuíra 
esfregou um facão na cara de José Antônio Muniz Lopes, então diretor de engenharia da Eletronorte, percorreu o mundo, tornando-se símbolo e uma espécie de logotipo da hostilidade total dos índios em relação às projetadas barragens. Enquanto os Kayapó estavam reunidos na Bethânia, as comunidades de Altamira se organizaram num ato público no bairro de Brasília. Levantaram sua voz contra os órgãos do governo que operam na surdina e excluem deliberadamente a sociedade civil da discussão de projetos que afetam a população e o meio-ambiente. A vitória estava do lado dos índios e de todos que se opuseram à a concretização do megaprojeto. Kararaô foi arquivado! Aparentemente!” (Krautler, 2005:11)

O Projeto, diante da reação das populações locais, com o apoio de organizações não-governamentais, partidos políticos de oposição, militantes políticos de tendências diversas, entrou em dormência e foi alterado para voltar à carga justamente no governo assumido pelos que eram críticos e contrários, no primeiro momento, à construção daquele empreendimento.

Para efetivar a obra foram implementadas estratégias de diluição das responsabilidades de execução técnica, cooptação de organismos corporativos, reorientação e alianças políticas que implicaram em conversões (ou degeneração) e apoios aos executores. Os argumentos apresentados iam desde à necessidade de aumentar a demanda para evitar um colapso do sistema energético do país, até a promessa de geração de emprego, renda, concessão de moradias dignas, reordenamento espacial e requalificação do espaço urbano (Falcão 2010).

De outro lado, os oponentes ao projeto pregaram, durante todas as fases, os alertas aos efeitos deletérios de empreendimentos deste tipo, demonstrando desde a deficiência técnica da proposição, à dilaceração do tecido social que se evidenciou com todas as cores nos anos que se seguiram.

Em 2005, sob a organização de Sevá Filho, professor da Universidade de São Paulo (USP), foi pulicado o livro Tenotã-Mõ, no qual pesquisadores, lideranças de movimentos sociais da região do Xingu, de organizações não-governamentais e procurador do Ministério Público Federal (MPF), apontam diversos impactos ao meio ambiente, às populações tradicionais e também urbanas, que poderiam ocorrer, se fosse construída a hidrelétrica (Sevá Filho 2005).

No momento em que este texto é escrito (2016), recorre-se às imagens do presente que traduzem parte do apocalipse anunciado pelos militantes, confirmado pelos discursos e sentimentos expressos pelos residentes e pessoas que vivem algum tipo de relação com a cidade e o meio rural.

\section{- TUMULTO COM OS NOVOS CHEGANTES}

O anúncio de liberação para o início das obras de Belo Monte provocou uma corrida para a cidade de Altamira. Vieram pessoas com habilitação 
para trabalhar na obra da barragem (pedreiros, marceneiros, operadores de máquinas, torneiros mecânicos, soldadores, eletricistas), nos serviços de apoio (cozinha, almoxarifado, secretaria, contabilidade, serviços gerais, segurança), técnicos de nível médio e superior, operários para serviços exigentes em pouca qualificação (ajudantes de pedreiro, serventes). Houve outras pessoas que se empregaram no terciário, em particular no comércio de alimentação, farmácias, confecções, hotelaria. Multiplicaram-se os serviços informais com uma enorme quantidade de vendedores de todos os gêneros.

Em 2013 estivemos acompanhando Sócrates $^{2}$ na pesquisa de campo que fizera em áreas que seriam inundadas e secas pela operação da barragem. Os hotéis estavam lotados, de forma que um dos pesquisadores não conseguiu vaga no que se hospedava preferencialmente, tendo que ocupar um outro próximo à estação rodoviária. Serviços bancários ficaram congestionados e para acessar um dos vinte caixas eletrônicos disponibilizados pela principal agência bancária da cidade, era inevitável enfrentar a fila. O número de motocicletas e carros na rua obrigou a que se instalassem semáforos, o que entretanto não evitou o aumento dos acidentes com os veículos e as pessoas.

\section{OS EFEITOS VISÍVEIS NA PAISAGEM}

Um casal, após ser desalojado pelo Consórcio Construtor de Belo Monte (CCBM), sai do Bairro do Itamarati onde morava em uma casa de madeira e palha, segundo as primeiras informações que obtivemos de terceiros. Pelas condicionantes estabelecidas no processo de negociação com a CCBM, a população afetada pela movimentação do empreendimento teria direito a uma casa ou a uma indenização que, no caso observado, não se efetiva, modificando o modo de vida daquelas pessoas, oferecendo à população local cenas de um drama humano de um realismo dramático. Esta dupla ocupou uma embarcação encalhada na beira do rio e passou a nela fazer moradia, conforme demonstra a Figura 1.

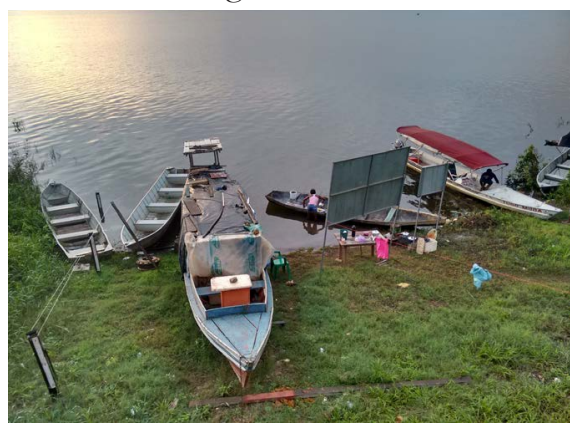

Figura 1. Da baixada para um barco na Beira do Rio. Foto Gutemberg Guerra, 18 de Janeiro de 2016

Pode-se demonstrar, com registro fotográfico feito a partir do mês de dezembro de 2015, o segundo desalojamento pela subida das águas após o fechamento das comportas. $\mathrm{O}$ volume de águas aumentando foi diminuindo o espaço de vivência do casal, até o momento em que o barco foi inundado, não restando-lhes outra alternativa senão a de se transferirem para o vão da rampa de acesso à margem do rio. Esse movimento ocorreu em pouco menos de uma semana, quando a água subiu, alagou o barco, obrigando a família a 
abandoná-lo e se instalar embaixo da estrutura da rampa de acesso ao rio. Para adaptarem esse espaço, usaram a lona e material que tinham utilizado para cobrir a embarcação que lhes servira de apoio até então, fizeram um biombo que lhes protegesse do sereno noturno e do escaldante sol equatorial, como se pode ver nas Figuras 2 e 3.

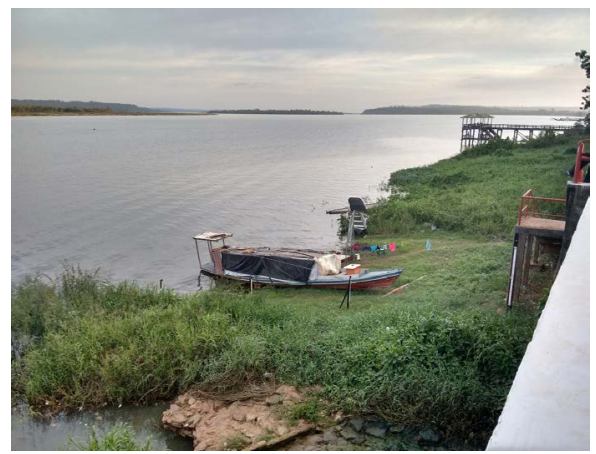

Figura 2. O barco e a rampa de acesso ao rio. Foto Gutemberg Guerra, 17 de Janeiro de 2016

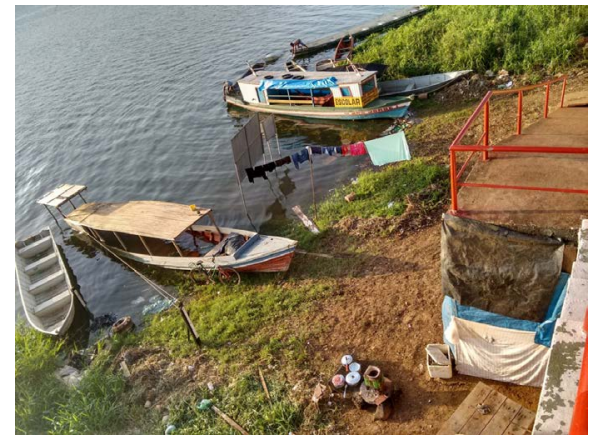

Figura 3. Do barco para debaixo da rampa de acesso à margem. Foto Gutemberg Guerra, 22 de janeiro de 2016.

Durante as manhãs, enquanto fazíamos caminhadas pela orla, presenciamos conversas telefônicas em que a senhora do casal falava com alguém, dando conta dos esforços que fazia para alugar uma casa na cidade. Relatava a dificuldade de encontrar o proprietário. É conhecido o padrão do mercado imobiliário de Altamira, inflacionado desde 2009, quando se anunciaram os procedimentos de início da construção. Embora o mercado tenha arrefecido com a retirada dos trabalhadores para os canteiros de obra, e depois com a demissão em massa dos operários que executaram a parte da obra física, os preços continuam altos e as casas disputadas pelos que dela necessitam.

No dia 25 de Janeiro de 2016, conversamos com esta senhora que disse se chamar Raabe, natural de Almeirim. Teria sido deslocada de vários pontos onde estabelecera moradia temporária. Antes em uma ilha rio abaixo, depois em outra ilha um pouco acima de Altamira, todas alagadas e de onde teve que sair. Tinha filhos mas eram crescidos. Vivia "do que as pessoas me dão". "Saio uma hora dessa (7 horas da manhã) e quando volto ao meio dia, sempre tenho alguma coisa para comer!". Estava de fato à procura de casa, mas os preços eram altos (650 reais por um quarto, segundo ela). E tinha muitas outras pessoas também querendo alugar. Não sabia para onde ia depois que a água alagasse o último ponto de ocupação que era aquele vão de rampa na beira do rio. Todos os rearranjos para estabelecer um local de moradia se desintegravam diante das novas ações demandas do empreendimento de construção da usina hidrelétrica. Não se trata apenas de uma forma de reorganização social e cultural ante as profundas transformações que ocorriam, mas também uma tentativa desesperada de encontrar um lugar 
seguro para ela e sua família viverem. A nesga de terra onde ainda podiam fazer seus trabalhos domésticos se estreitava cada vez mais e em breve seria completamente alagado e perderíamos de vista os seus moradores.

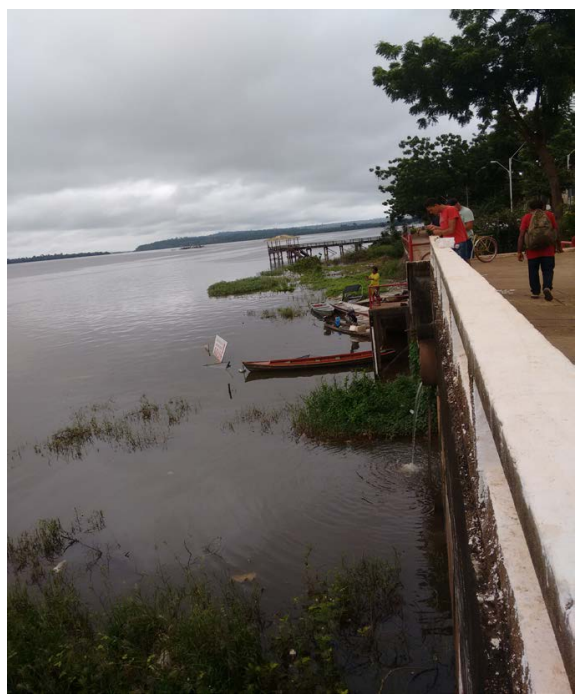

Figura 4. Vão da escada de acesso à margem alagado e pescaria no esgoto. Foto Gutemberg Guerra, 14 de março de 2016

Este é o registro fotográfico de um dos dramas humanos que se estabeleceram com a implantação da barragem e os seus efeitos colaterais, tanto quanto outros que narramos a seguir.

\section{PROMESSAS E CONDICIONANTES}

Ao lado da cena em que se expõe a vida das pessoas em detalhes, como as panelas dispostas na relva que se encolhe com o avançar das águas, as roupas no varal e uma caixa térmica, um esgoto despeja dia e noite, água putrefata. Duas manilhas, uma mais estreita, segundo um morador antigo daquele trecho, o sr. Ananias, 74 anos, trazia o esgoto das casas mais próximas, em direção ao rio. A empresa contratada para fazer o serviço de saneamento canalizou com uma tubulação avantajada de mais ou menos um metro de diâmetro, a água servida de vários quarteirões, inclusive do Hospital Regional e do quarteirão onde funciona a Feira Coberta e mercado municipal, para despejar naquele ponto. Assistimos e registramos com fotografias pescadores fazerem sua atividade justamente ali, em frente ao esgoto, conforme demonstram as Figuras 4 e 5.

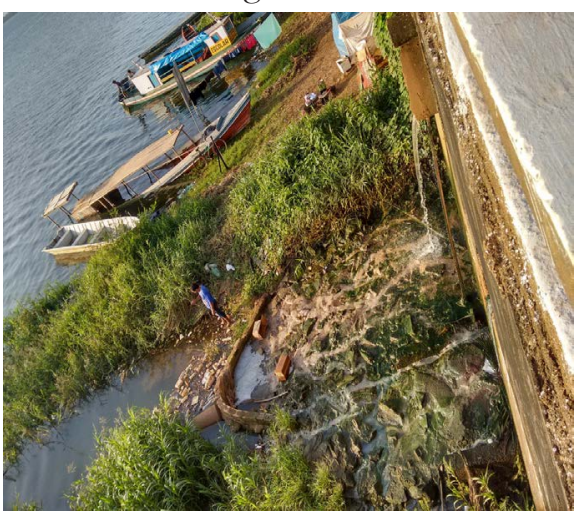

Figura 5. Pescaria no esgoto. Foto Gutemberg Guerra, 23 de Janeiro de 2016.

Quando dos debates e denúncias sobre o CCBM, foram estabelecidas condições que deveriam ser atendidas como contrapartida pelo empreendimento em curso. Essas condições, tratadas corriqueiramente como condicionantes, são promessas de realização de estruturas que cumprem dois papeis: o de minorar a reação da sociedade civil organizada contra os efeitos deletérios desse tipo de empreendimento e criar e manter uma imagem de responsabilidade social tanto do governo (municipal, es- 
tadual e federal) como das empresas envolvidas na execução do projeto.

Gomes (2009), em estudo sobre as propostas de mitigação de impactos, constantes no Estudos do Impactos Ambientais (EIA), com a construção da hidrelétrica, publicado em um Painel de Especialistas, aponta graves problemas sobre a infraestrutura urbana da região. Para a autora, segurança pública, educação e saúde, não estavam sendo abordados adequadamente nos projetos e estudos oficiais, o que dificultaria significativamente a vida das populações da região, quando necessitassem acessar serviços públicos essenciais.

Por outro lado, o CCBM com frequência propagandeia que o empreendimento propiciaria a construção de uma infraestrutura adequada às cidades da região, principalmente Vitória do Xingu e Altamira. A previsão anunciada em grandes cartazes registrados em setembro de 2014 é de que "Altamira em breve será uma das poucas cidades do Brasil a ter água e esgoto tratados", conforme demonstrado na Figura 6. O mais preocupante é que este não é o único ponto de descarga de esgoto da cidade no Rio Xingu, podendo-se encontrar muitos outros, inclusive canalizando esgoto de hospitais, com este mesmo destino. Mais do que isso, uma praia artificial construída na mesma orla, cercada destes pontos de descarga, tem sido usada pela população sem nenhuma advertência sobre a balneabilidade neste local.

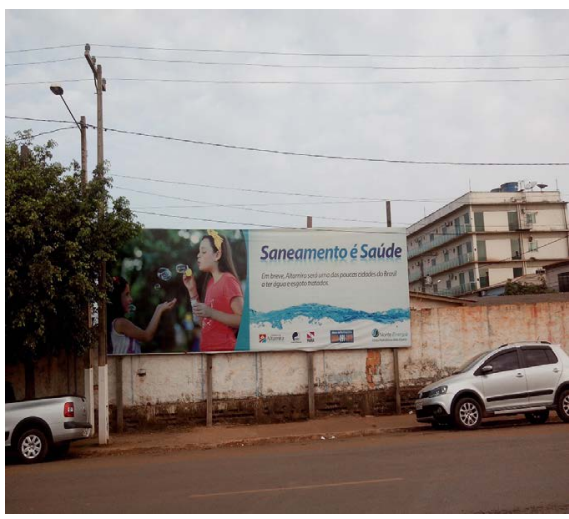

Figura 6. Outdoors prometendo Saneamento básico. Foto Gutemberg Guerra, Setembro de 2014.

\section{OS ESQUECIDOS}

Moradores de rua, ou pessoas que tem na rua o seu ponto de permanência durante a noite, em geral homens jovens embriagados, exibindo garrafas de cachaça e cerveja ou latas de cervejas em plena manhã, alojavam-se na relva, nas marquises das casas comerciais ou das barracas e quiosques existentes em Altamira, ou ainda nas instalações do embarcadouro que se construíram no cais. Sinais de que ali estavam com o seu cotidiano podem ser vistos na figura 7. Com o enchimento do rio e a movimentação da população nestes espaços, estas pessoas ficaram sem ter para onde ir, pelo menos nas semanas em que foram registrados estes fatos. Uma cena que chamou a atenção foi a das águas subindo e os moradores de rua retraindo-se paulatinamente até se inviabilizar o espaço de suas moradias. Um indicador dessa situação foi registrado com os 
pertences, entre os quais um colchão encostado no paredão a poucos metros da água crescente (figura 8). Em seguida houve a inviabilidade de uso daquele espaço pelo alagamento total da área pelo rio, de um lado, e de outro por uma manilha que despejava o esgoto (Figura 9). O colchão foi visto na contenção com o seu dono dormindo nele em pleno sol, correndo sério risco de desidratação, o que poderia ser entendido como uma forma de protesto veemente ou de desespero (Figura 10). Pelo menos dois desses moradores foram vistos na contenção de pedras que foi feita para formar a praia artificial, apresentando comportamento alterado, agressivo entre eles mesmos. Não foi registrado nenhum trabalho de assistência social a estes indivíduos desde que se acompanhou estas cenas, com registros iniciados em 2015.

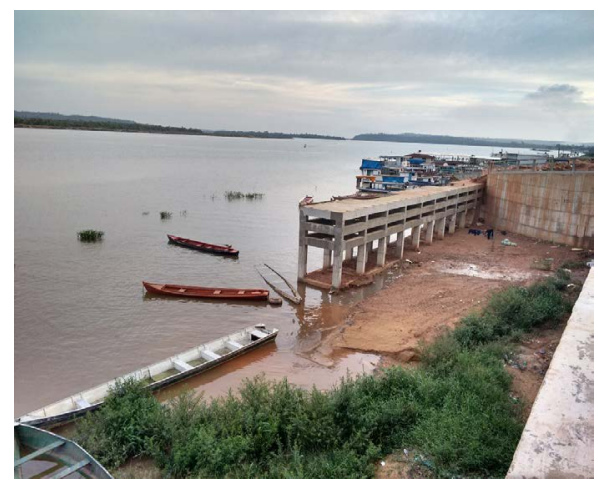

Figura 7. Moradores de rua abrigados no ancoradouro em construção. Foto Gutemberg Guerra, 20 de Janeiro de 2016.

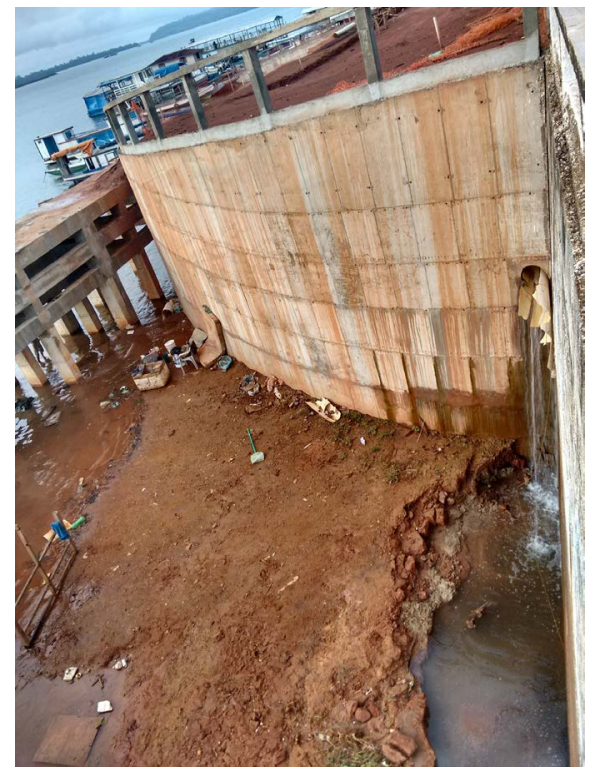

Figura 8. Ameaçados pela água do rio e pelo esgoto. Foto Gutemberg Guerra, 21 de Janeiro de 2016

Zhouri (2012) considera que Belo Monte se transformou em um símbolo do não funcionamento adequado da democracia no Brasil, pois em nome do progresso e do desenvolvimento diversos atores tiveram seus direitos desrespeitados, incluindo o meio ambiente. Para a antropóloga, não se respeitaram os direitos das pessoas que perderam propriedades ou modos de vida com a construção da barragem, pois "a categoria de atingido refere-se apenas aos grupos que se localizam na área imediatamente sujeita a alagamento" (Zhoury 2012:57). Esta interpretação sobre os atingidos, se tornou em uma barreira para muitas populações tradicionais e urbanas, terem acesso a reparações para as perdas que sofreram.

Block (2012), problematizando a obra de Polanyi, afirma que, quando o capi- 
tal buscou atribuir preços aos humanos e à natureza, acabou demonstrando de forma dramática que os mercados não podem ser desregulados, pois colocam em risco a existência da vida, inclusive a humana, ao dessacralizá-la:

"O argumento de Polanyi se desdobra em dois níveis. O primeiro é uma consideração moral de que é errado tratar a natureza e os seres humanos como objetos cujos preços são determinados totalmente pelo mercado. Esse conceito transgride os princípios que governaram as sociedades durante séculos: quase sempre se reconheceu que a natureza e a vida humana têm uma dimensão sagrada. É impossível reconciliar essa dimensão sagrada com a subordinação do trabalho e da natureza ao mercado." (Bloch 2012: XXXV).

Os desabrigados não são percebidos como dotados de direitos em sua plenitude e, ao mesmo tempo, passaram a se constituir apenas em obstáculos que podem ser contornados ou adequados para que o empreendimento seja posto em prática. Natureza e vida humana são percebidos enquanto entraves, na construção de Belo Monte, os quais podem ser retirados, adequados ou receberem um preço, como uma indenização, que pode ser pago para garantir as obras, mas sem possuir um valor e direitos em si mesmos, pois a importância da obra se mostra superior ao meio ambiente e às pessoas.

O limiar entre ter um abrigo e não o ter, neste processo de tornar o empreendimento operacional, é cada vez mais tênue, inexorável para os mais fragilizados socialmente. E quem são eles? Alguns vindos no mesmo processo como trabalhadores ou na esperança de trabalho por conta da usina. A imagem registra com nitidez o império da força bruta e a despreocupação com a saúde. O lixo boia na margem inundada, misturando-se à vegetação que não resistirá!

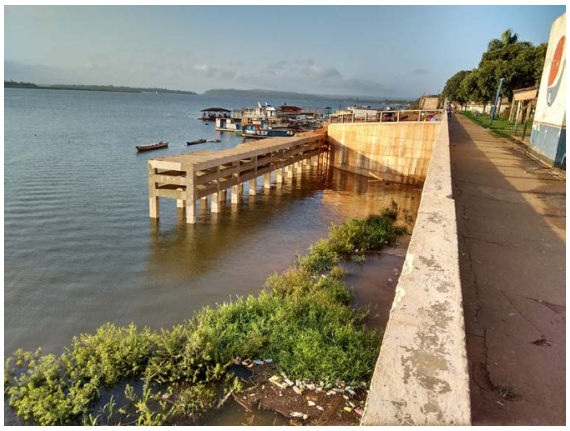

Figura 9. O ancoradouro apenas para barcos. Foto Gutemberg Guerra, 23 de Janeiro de 2016

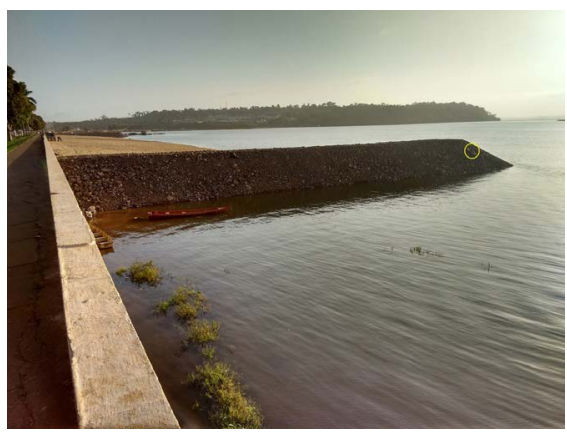

Figura 10. Desalojado com seu colchão na contenção da praia artificial (círculo amarelo). Foto Gutemberg Guerra, 22 de Janeiro de 2016

No dia 24 de janeiro o colchão se encontrava no canto do cais com a contenção de pedra, assim como outros pertences daquele desalojado que se juntava a um grupo de 15 homens que se embriagavam e conversavam entre a relva e a calçada que margeia o cais. 


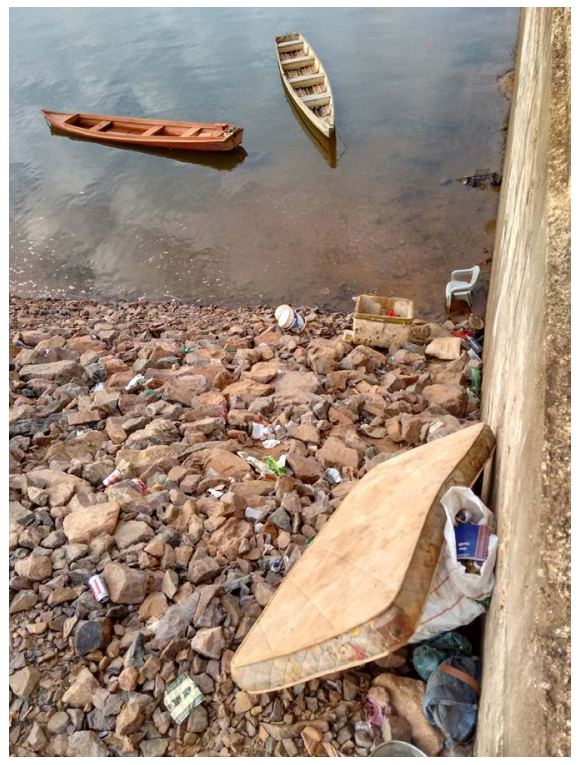

Figura 11. Pertences de morador de rua desalojado pelas águas. Foto Gutemberg Guerra, 24 de Janeiro de 2016

Poderia ser uma cena de filme ao estilo do diretor surrealista Luís Buñuel, como em "Los olvidados". Estas pessoas existem concretamente, mas se tornaram esquecidas aos olhos das empresas públicas e privadas responsáveis pela obra, ainda que estejam cotidianamente diante delas.

Ao problematizar os emblemas da modernidade, Latour analisa que a queda do Muro de Berlim e a descoberta do aumento do buraco da camada de ozônio, em 1989, explicitaram para as democracias ocidentais que substituir a exploração dos seres humanos pela exploração desmedida da natureza, pode inviabilizar a existência dos fundamentos das sociedades. Para ele, "ao tentar desviar a exploração do homem pelo homem para uma exploração da natureza pelo homem, o capitalismo multiplicou indefinidamente as duas"
(Latour, 1994:14). Na mesma proporção em que se acirraram as preocupações com as problemáticas ocidentais nos países desenvolvidos, ocorreu um novo aumento da busca por explorar novos espaços do globo, o que acelera a miséria destas populações, desprovidas de direitos e esquecidas pelos organismos internacionais.

\section{DE GANGUES LOCAIS A CRIMINO- SOS PROFISSIONAIS}

Os relatos sobre violência ouvidos antes da chegada dos operários da CCBM e dos chegantes que vieram para compor o burburinho que Altamira passou a viver, eram sobre ameaças por criminosos locais, dos quais o nível de agressão relatada era algo com o qual se convivia com receios, mas sem o grau de temor que se acentuou.

Antes do Belo Monte, um fato estranho se deu ao observarmos que os estudantes e professores não utilizavam um campo de terra batida existente no Campus II da Universidade Federal do Pará, onde se ministrava o Curso de Ciências Agrárias. Situado no terreno com cercas, mas com as porteiras vulneráveis da instituição, havia sempre jovens moradores do local naquele espaço para a prática esportiva. Foi dito por um professor, praticante de futebol de salão, que a quadra do Campus I, onde havia instalações utilizadas pela administração do Campus e os cursos de licenciatura em Letras, Pedagogia e Biologia era o território de domínio dos universitários e de fato, ali havia sempre estudantes em disputas de futebol, basquete e vôlei. Ouvi, do mes- 
mo professor, relatos de que uma gangue teria tomado conta da quadra de esportes daquele campus universitário II, conhecido vulgar e pejorativamente por Curral, por conta de ser utilizado pelos cursos de ciências agrárias. De fato, eram grupos de jovens moradores dos arredores do campus que praticavam o futebol naquele terreno aberto, antes do cercamento feito pela administração da Universidade Federal do Pará. Ao circular por aquela área, nas ruas próximas ao Campus e ao Cemitério da Cidade, o professor manifestava o temor de ser assaltado, relatando ocorrências sem entrar nos detalhes ou personalizar as vítimas.

A professora Agnes, do Campus de Marabá, ministrando aulas no Campus de Altamira, em 2014, relatou ter sido atacada por uma mulher com problemas mentais que morava nas proximidades do Campus, em uma vila de casas situadas na Rua Coronel José Porfírio. Essa mulher era sempre vista em trajes mínimos e quando em surto psicótico, assumia comportamento agressivo, conhecido de toda a população local e universitária.

Em 2014 e 2015, os relatos passaram a ser de outros tipos de agressão. O professor Xenofonte, ao chegar em sua residência, ao descer do carro, com sua família composta de esposa e dois filhos, foi rendido por dois assaltantes armados de revólveres. Foram todos trancados no banheiro da casa enquanto os assaltantes se apropriavam de objetos como joias e eletrodomésticos, fugindo em duas motocicletas. Xisto, egresso do Curso de Agronomia do Campus de Altamira, estava no quin- tal da casa de um casal de amigos em uma noite de sábado, quando foram abordados por dois jovens armados de revólveres calibre 38, rendidos, colocados no banheiro da casa, enquanto os bandidos levavam pertences da casa e as motocicletas de Xisto e do seu amigo que estavam estacionadas na frente da casa. Deram parte à polícia, mas não tiveram os seus bens recuperados. O casal João e Joana, em 18 de dezembro de 2015 , foi a um casamento de parentes em Brasil Novo, município vizinho de Altamira. Deixaram sua residência trancada, com cães de guarda que circulavam na casa vizinha, dos pais de Joana que também haviam ido ao mesmo evento. Ao retornarem, encontraram sua casa depredada e seus eletrodomésticos e computadores de trabalho ausentes. Os ladrões teriam entrado pelo telhado da casa e os cães nada puderam fazer senão latir e serem encontrados completamente excitados. O casal relatou que outros crimes dessa mesma modalidade teriam sido praticados no bairro, recentemente (final de 2015). Suspeitavam de população que se estabelecera no Reassentamento Urbano Coletivo (RUC) ${ }^{3}$ instalado nas proximidades, alocando moradores dos bairros que se situavam nas áreas de baixada de Altamira, conhecidos pela violência que ali era praticada por alguns criminosos que viviam como moradores daquela área.

Maísa, recepcionista do Xingu Hotel, relatou em 23 de janeiro de 2016, que uma de suas colegas foi assaltada na rua Lindolfo Aranha, localizada a duas ou três dezenas de metros do seu local de trabalho, em outubro de 2015, 
às 7:30 da manhã, tendo seu celular e documentos perdidos.

No restaurante popular próximo ao Banco do Brasil em que almoçamos em dezembro de 2015, dois operários conversavam sobre assaltos que se faziam às portas de hotéis, a outros operários, por ladrões armados e que chegavam de motocicletas. Irados, manifestavam o desejo de eliminação sumária dos assaltantes.

Em um restaurante popular, próximo à universidade, um dos pesquisadores almoçou junto com o diretor da Faculdade de Ciências Agrárias. Habituado a fazer refeição naquele espaço e privar da boa relação de amizade com os proprietários, filhos de camponeses pioneiros da Transamazônica, fomos recebidos por eles que ficaram próximos à mesa que ocupamos, contando histórias do período da colonização e algumas sobre a movimentação da cidade. Entre essas, Dona Carla relatou ter visto, na noite anterior, por volta das 20 horas, uma senhora ser assaltada na esquina que fica a uns 20 metros do seu estabelecimento. No relato, detalhes da ação, com o assaltante empunhando um revólver, tomando os pertences da senhora, diante do olhar e comportamento passivo e amedrontado dos expectadores. A senhora assaltada, depois do crime, veio para o restaurante, de onde foi acionada a polícia para uma infrutuosa busca e apreensão do que fora furtado.

A compreensão de um professor do campus sobre a recente incidência de crimes praticados a mão armada, por grupos de criminosos que teriam vindo na leva da construção da barragem, estaria associada ao aumento do público que chegou a 24 mil trabalhadores diretamente no canteiro de obras e mais de 16 mil trabalhando indiretamente com o empreendimento no auge da construção, no final de 2014 (Borges 2015), reduzindo-se drasticamente para menos de cinco mil no segundo semestre de 2015.

Gomes (2009) ao analisar os problemas que Belo Monte poderia ocasionar, conclui que propiciaria o aumento da violência na região, em função do crescimento populacional e do agravamento da desigualdade e da exclusão. Este problema seria multiplicado caso não fossem implementadas, antes e durante a construção da hidrelétrica, medidas sociais para o seu enfrentamento. A autora considera também que o crescimento do número de ocorrências policiais, devido à chegada de grande contingente de pessoas, seria uma consequência esperada. O problema da violência urbana exigiria, por parte dos construtores e dos órgãos públicos, grandes investimentos em infraestrutura de segurança pública e também em políticas sociais de inclusão.

Ao que se pode perceber em uma leitura atualizada sobre a região, não foram implementadas de modo satisfatório as medidas necessárias, o que gerou um progressivo aumento da violência, oprimindo ainda mais a população de Altamira e de Vitória do Xingu. Estes municípios, segundo um policial civil nos relatou, em 2007, não possuíam crime organizado, mas apenas o que denominou de "cheira-cola", os dependentes químicos que praticavam 
pequenos furtos ou "pediam pedágio" para obter um pouco de dinheiro para comprar narcóticos.

Pedir "pedágio" se constituía em uma prática adotada sobretudo por dependentes químicos e de bebidas alcoólicas. Estas pessoas geralmente em grupo, se reuniam em algumas esquinas, principalmente durante às madrugadas e em bairros afastados do centro da cidade, para exigir pequenas quantias de dinheiro, variando entre 2 a 10 reais, para que permitissem a passagem dos transeuntes. Esta prática, relatada pelo policial civil, em 2007, ocorria com frequência antes da construção de Belo Monte e se tornou, nas memórias de muitos moradores da cidade, em símbolo dos "bons tempos" em que os crimes se resumiriam principalmente a estas ações e eventualmente a lutas entre gangues de jovens.

Atualmente, os telejornais locais, trazem com frequência notícias sobre ações do crime organizado, arrombamentos a residências e comércios, assassinatos e até mesmo assaltos a mão armada durante o dia, no centro de Altamira, o que gerou um clima de insegurança na cidade.

\section{AS FALAS TEMEROSAS E O TOQUE MUDO DE RECOLHER}

O clima de insegurança foi instalado progressivamente após a chegada de muitos estrangeiros e de pessoas de diversas partes do país, inundando a cidade, saturando as filas de bancos, farmácias, supermercados e lojas de todos os ramos comerciais, ao mesmo tempo em que aumentava o número de acidentes e de incidentes criminosos. Generalizou-se o discurso da insegurança que pode ser ouvido desde os guardas do campus universitário da UFPA de Altamira, pelos professores, funcionários, estudantes e pela população em geral.

Praticante da caminhada matinal na orla de Altamira desde que a frequenta nos anos 1990, um dos autores ficou alojado no Campus II da UFPA em dezembro de 2015. Todos os dias, ao sair, por volta de 5 e 5:30 da manhã, foi alertado pelos seguranças que trabalham naquele espaço para tomar cuidado. Recomendaram que fizesse os exercícios físicos na praça gradeada recém-inaugurada, onde havia um vigilante de plantão e que abria para as pessoas que solicitavam o espaço para este fim, o que era feito por um certo número de pessoas da cidade que tinham a mesma prática que o referido autor. Preferiu sempre fazer isso caminhando pela orla, nela encontrando outras pessoas fazendo a mesma coisa. Não ouviu nenhum relato de agressão dos que estavam fazendo exercícios físicos na madrugada, em geral pessoas com aparência de mais de quarenta anos, portando não mais do que as roupas e calçados apropriados para este fim.

Nos finais de semana, caminhando um pouco mais tarde, entre 7 e 9 horas da manhã, o público encontrado, além dos atletas matinais, eram os ébrios moradores de ruas e jovens amanhecidos depois de farras em boates ou domicílios desde a noite anterior. $\mathrm{O}$ comportamento alegre e cordial entre eles ignorava os passantes, desfazendo 
qualquer sensação de ameaça que se pudesse ter.

Os temores manifestados pelos moradores de Altamira se expressavam no discurso e na prática. Todos passaram a ser mais cautelosos em portar discretamente ou não carregar aparelhos telefônicos, computadores, joias, relógios de pulso ou adereços que pudessem atrair a cobiça de assaltantes. $\mathrm{O}$ uso de mochilas, simplesmente, atrairia a cobiça dos donos do alheio.

O clima de insegurança se reforçou com a morte de um policial, em dezembro de 2015, e com o imediato assassinato de nove pessoas. O fato é que as pessoas passaram a evitar circular à noite, mesmo em espaços muito vigiados e com a presença do policiamento ostensivo, como a orla do cais. Antes das dez horas da noite, as ruas se encontram desertas ou com movimentação claramente reduzida.

Um dos autores saiu algumas vezes com um casal de ex-alunos para jantar. Fizeram sempre questão de o levar para o Hotel de motocicleta ou acompanhar até que lá chegasse, a título de não lhe deixar trafegar sozinho pelas ruas da assustada cidade.

Não há como negar que esta nova realidade, da insegurança como um componente do cotidiano da cidade, seja um problema social trazido à cena com a construção da hidrelétrica. Os moradores da cidade que, antes da obra, conheciam conflitos entre gangues de jovens e pequenos furtos ou raros assaltos a residências e pontos comerciais, passaram a sentir medo nas ruas da cidade. Circulam pelas ruas viatu- ras policiais com a inscrição da Norte Energia, como doadora, mas para enfrentar o que Bermann denominou de "mega-obra gigantesca, com custos enormes, com consequências ambientais e sociais seríssimas" (2012: 89) é necessário forte investimento em infraestrutura urbana, incluindo lazer, atividades socioeducativas e inclusão social e não apenas em equipamentos policiais.

Nesse sentido alguns espaços de lazer foram reformados ou remodelados como ocorreu com a Praça da Independência, ao lado do Campus da UFPA. O espaço foi remodelado, recebendo pistas para caminhada, patinação e skate, quadras de futsal e quadra de vôlei de areia, coreto reconstruído, anfiteatro e quiosques de lanches. Esta praça passou a se constituir em um novo espaço de lazer frequentado por muitos moradores, pois conta com segurança e sendo toda gradeada, fica aberta das 6 às 23 horas.

Em espaços como estes, os moradores reconstituem práticas de lazer e sociabilidade, pois o aumento da violência os empurrou cada vez mais para o interior de lugares fechados. Como efeito da construção da hidrelétrica e da chegada de novos moradores, surgiram também espaços para jogos eletrônicos, novas lanchonetes e novos restaurantes, muitos dos quais seguindo um padrão até então inexistente em Altamira, por se constituírem em bistrôs e lanches característicos de grandes centros urbanos.

A população aturdida em um primeiro momento por um cenário bem dife- 
rente do que muitos moradores acreditaram que seria o propalado desenvolvimento propiciado por Belo Monte, foi aos poucos reconstruindo suas práticas, buscando alternativas para o lazer.

\section{OS REALOCADOS OU IMPACTADOS}

Manoel, 64 anos, natural de Altamira ${ }^{4}$, tem uma casa na orla e era dono de uma ilha herdada da família, rio acima. Foi indenizado pela Norte Energia em 110 mil reais que lhe são pagos sob condições. Foi comprada uma terra pela própria empresa que lhe fez a troca pela anterior, mais $\mathrm{R} \$ 80$ mil reais que estão sendo pagos sob condição de que ele demonstre com o que está sendo gasto o dinheiro da primeira prestação de 27 mil reais, a segunda, de 28 mil reais e uma terceira ainda por receber. Ele tem que levar as notas de suas compras que são analisadas pela empresa e liberado ou não o recurso. Ele se queixa de que lhe foi tomado o terreno com benfeitorias e entregue outro sem casa, sem energia, sem estrada e com 7 cabeças de gado bovino e 40 de ovinos que pertencem a outras pessoas. Este gado solto e bravio está no terreno mas dele não pode dispor o Manoel por não ser de sua propriedade.

O Instituto Socioambiental (ISA), organização não governamental que desenvolve diversos trabalhos junto a populações tradicionais no Brasil, incluindo a região do Xingu, publicou um Dossiê, no qual destacou problemas sofridos por famílias de ribeirinhos expulsas de suas terras, devido ao processo de alagamento, com as obras de Belo Monte. Estas pessoas estariam, segundo o ISA, sofrendo com a perda de condições de manter seus modos de vida:

"As famílias que residem nas ilhas e margens do rio Xingu têm sido obrigadas a sair de suas casas e áreas produtivas sem uma nova moradia que garanta condições de vida iguais ou melhores às anteriores. Os projetos de reassentamento são distantes do rio, impedindo que essas famílias continuem a exercer sua principal atividade, a pesca." (ISA 2015).

Manoel tem uma canoa que se encontrava alagada no dia 24 de janeiro de 2016. Fez um discurso temeroso de como tem subido a água, antes de centímetro em centímetro, agora (janeiro de 2016) de metro em metro, e sem estar chovendo nem nas cabeceiras nem em Altamira. Teme que quando se combinarem as chuvas da cabeceira, com as que caiam na cidade, mais a água represada, o efeito seja desastroso. Lembra o desespero dos que sofreram com as primeiras chuvas torrenciais em Altamira, quando houve alagamento e muitas queixas dos moradores de áreas inundáveis ainda sem a devida drenagem. Vivia de colher frutos de manga (Mangifera indica, L), muruci (Byrsonima crassifólia (L.) Rich), caju (Anacardium occidentale, L), tucumã (Astrocarium tucuma, G. Mey) e outros que existiam no seu terreno. No atual, está se preparando para fazer roça de mandioca, milho e feijão e tem expectativa de ser positivo por conta de que o terreno estava em pousio $^{5}$.

É a expectativa da tragédia que tem 
marcado os ribeirinhos desde que foi iniciada a construção da barragem. As informações que recebem são desencontradas o que aumenta seus temores de se verem obrigados (como muitos já foram) a sair de suas terras onde vivem e se estabeleceram há gerações para passar a morar na zona urbana de Altamira. Para o desembargador federal, Antônio Souza Prudente, a construção da hidrelétrica "certamente irá atingir as comunidades indígenas e ribeirinhas do rio Xingu não só nos aspectos de ordem de impacto físico-ambiental, mas também de ordem cultural e, finalmente, de ordem moral" (Prudente 2010:38).

Nesse quadro, para além dos sonhos de progresso e desenvolvimento, a construção de Belo Monte, se constituiu no pesadelo dos ribeirinhos que temem ser arrancados de seus lugares, suas vidas, seu cotidiano, da proximidade física com seus vizinhos e parentes e de suas práticas culturais, marcadas pelos ritmos da natureza.

\section{DE PORTO RÚSTICO A EMBAR- CADOURO DE CONCRETO AR- MADO}

Uma transformação estrutural que deve ser levada em consideração é a lógica de atracação que vem sendo radicalmente modificada em termos de sistema. As embarcações atracavam na margem do rio, diretamente na terra ou em pequenas rampas feitas improvisadamente. As pessoas adentravam as embarcações diretamente da água rasa para escadas ou rampas portáteis penduradas ou utilizadas como acessórios dos barcos. O material transportado pelas embarcações vinham em bicicletas, motos, carroças, camionetes e caminhões até a beira do rio, sendo feito o translado de um módulo para outro diretamente. Esse sistema permite que praticamente toda a margem do rio em Altamira servisse de porto ou estação de transbordo, sem a exigência de estruturas de armazéns ou entrepostos, menos ainda de maquinário como guindastes, roldanas ou polias. $\mathrm{O}$ alagamento da margem não permite a manutenção desse sistema, exigindo a construção de embarcadouros, estacionamento para veículos terrestres, o que vem sendo feito. Nota-se porém que a diminuição da área de atracação exigirá que se façam boias, ou as embarcações terão que utilizar sistemas de poita e âncora para manter os seus veículos próximos ao embarcadouro. Quanto ao estacionamento de veículos, deverá aumentar a sua demanda, aumentando a concorrência na orla onde esse transporte tem parte de sua demanda atendida.

Na manhã de 23 de janeiro, encontramos várias pessoas contemplando perplexas ou arguindo sobre até onde a água iria chegar. Comparando com o desmatamento feito na ilha em frente de Altamira, a impressão era de que havia muito ainda a ser alterado no nível das águas. Quanto? Era a pergunta enrugada nas testas das pessoas. Conversando com Casé, nativo de Altamira, no mesmo dia, ele indicou uma marca no paredão do cais, dizendo ser aquela a marca do rio no inverno. Segundo ele mesmo, o pessoal da CCBM teria feito uma marca da cota onde o rio chegaria, 
no mesmo paredão. Essa marca seria no mesmo ponto que indicava a cota do rio cheio no período chuvoso.

A paisagem transformou-se rapidamente, seja pela movimentação dos barcos na margem esquerda, comprimidos pela água que eliminou a vegetação em frente ao cais, na margem do rio, como pelo desmatamento promovido para as mudanças nas baixadas e no reordenamento urbano, tanto quanto pela supressão da vegetação nas ilhas. Nero, natural de Altamira, moto taxista, 32 anos, foi taxativo: "Altamira esquentou muito depois que fizeram esse desmatamento do lado de lá! Era de lá que vinha a brisa! Agora está muito quente!" 6

Aretusa, recepcionista de hotel, natural de Altamira, 42 anos, confirma: A água do rio já é quente, com esse desmatamento que a gente está vendo e mais o que a gente não vê, muda muito o clima! Mas eu gosto de calor! Não me dou bem em lugar frio, não! ${ }^{7}$

A percepção sensorial das pessoas, tanto do ponto de vista visual quanto da sensação térmica são elementos que devem ser considerados nessa análise. O senso crítico manifestado se reforça com uma visão temerosa, apocalíptica, associada ao que está se fazendo com a natureza.

Zhouri (2012) afirma que a natureza é vista no Brasil, como barreira ao desenvolvimento e a consolidação da competitividade do país para se inserir em um mercado global. Desta forma, os impactos causados ao meio ambiente não são considerados como graves problemas nacionais, mas ape- nas como algo que precisa ser contornado para garantir a implementação de mega-obras que permitam o progresso econômico.

A forma encontrada para amenizar os impactos ambientais são as "compensações", adotadas como medidas reparadoras que, segundo as propagandas oficiais, permitem o desenvolvimento sustentável da região e do país. Mas a população de Altamira, lamenta a perda da paisagem em frente a cidade, devido às ilhas desmatadas e queimadas e também a sensação de calor que acusa perceber. Magalhães \& Hernandez (2011), diferentemente das propagandas, avaliam como impossível compensar as perdas ambientais impostas ao rio Xingu.

\section{A DEPRESSÃO}

Em 2012, após um período de três anos e meio afastado para o doutorado, um dos autores retornava à Altamira e encontrou a cidade transformada, no auge da construção de Belo Monte. $\mathrm{O}$ cotidiano da cidade passava por alterações profundas, o que deixava a sensação de haver regressado a um lugar diferente de onde saíra, em 2009. O comércio estava muito movimentado, com novas lojas surgindo a todo momento e as antigas se deslocando pela cidade, buscando preços de aluguel mais adequados às suas possibilidades.

Pontos comerciais abriam e fechavam com facilidade, grandes empresas, inclusive conhecidas nacionalmente, como as Lojas Americanas, se estabeleceram na cidade. Pequenos mercados 
passaram a se tornar supermercados, outros fecharam, por não conseguirem se adaptar à nova realidade. Itens importados passaram a ser encontrados nas prateleiras, para atender às demandas de muitos novos moradores e havia carência de atendentes e vendedores, os quais exigiam salários acima da média estadual ou nacional para aceitar os postos de trabalho oferecidos.

Os preços no comércio eram remarcados com muita frequência, gerando uma sensação de inflação muito grande na população e também a exclusão de muitas pessoas. Surgiram pedintes pelas ruas, algo incomum até então, e também um número cada vez maior de moradores de rua.

Os preços de aluguel dispararam em pouco tempo e puxavam com eles os valores adotados no comércio, devido às dificuldades que encontravam para pagar o aluguel dos pontos comerciais. Mas ainda assim, os grandes comerciantes e donos de imóveis comemoravam, pois conseguiam auferir em pouco tempo, lucros consideráveis, nunca vistos até então. Apesar de uma parcela da população haver sido obrigada a migrar para municípios próximos ou até mesmo Santarém, como um casal de amigos o fez, operários e comerciantes comemoravam os ganhos que obtinham, atribuindo-os a Belo Monte. O preço, por exemplo, de aluguel de uma casa no centro da cidade, com três quartos, que antes custava em torno de quinhentos a setecentos reais, poderia ser encontrado entre três a cinco mil reais, dependendo do bairro e do tamanho do imóvel.
Com o passar do tempo, a partir da segunda metade de 2015, houve a planejada redução de mão-de-obra no empreendimento e o consequente esvaziamento da cidade, o que podia ser percebido, por exemplo, nas gigantescas filas de bancos drasticamente reduzidas e o comércio sentiu o novo momento. Muitos pontos comerciais fecharam, pois com a saída de milhares de pessoas, diminuiu a circulação de recursos. Os comerciantes que investiram para obter maiores lucros passaram a encontrar dificuldades para pagar as dívidas contraídas. Cresceu o número de demissões e de modo proporcional aumentou a violência e o empobrecimento da população. Altamira foi um dos dez municípios brasileiros que mais demitiu em 2015 e um dos que mais contratou em 2011 e 2012.

Há muitas placas de "Aluga-se ou vende-se" espalhadas por toda a cidade e os proprietários que não aceitam reduzir os valores ficam com seus imóveis desocupados. Podem ser encontradas, no centro da cidade, vilas inteiras aguardando possíveis novos locatários. A nova realidade do momento vai além da crise econômica nacional, pois aponta que, na construção de mega-obras de infraestrutura, a população local não é o fim do empreendimento, mas um meio para que ele possa ser implementado. Essas pessoas podem ganhar muito dinheiro em pouco tempo e perder muito mais em longo período, como acontece em Altamir. Como afirma Martins (2003), as sociedades marcadas por um senso utilitarista da natureza, tendem a lhe atribuir importância somente quando ela passa 
a ser modificada pelos humanos com objetivo de lhes proporcionar "melhorias de vida”. Desta forma, rios, fauna, flora e todas as práticas culturais a eles relacionadas perderiam o sentido em si mesmas, pois seria necessário extrair algum uso da natureza, através do esforço humano, como teria ocorrido na construção de grandes empreendimentos na Amazônia, como Belo Monte.

\section{CONSIDERAÇÕES FINAIS}

O reposicionamento dos atores sociais e políticos foi um dos mais dramáticos efeitos corrosivos da barragem de Kararaô, renomeada para Belo Monte e assumida por um conglomerado de grandes empresas construtoras financiadas com recursos estatais. Rememorando a trajetória dos debates sobre Kararaô e Belo Monte, Krautler lamenta que "muitos de nossos conterrâneos sonharam novamente com rios de dinheiro que inundariam nossas cidades" (Krautler, 2005:10), o que foi utilizado pelas empresas postulantes a construtoras e órgãos oficiais, a persuadir os moradores a apoiar a construção de Belo Monte.

Uma comerciante de Altamira, com quem dialogamos no momento em que escrevíamos este texto, lamentou a violência, o aumento no número de acidentes de trânsito e as perdas financeiras geradas "pela maldita Belo Monte" 8 . Ao ouvi-la falar com amargor sobre a hidrelétrica foi impossível não recordar que ela mesma estava, em 2007, participando de diversos debates sobre a obra, como uma das mais ardentes defensoras da construção da hidrelétrica e crítica dos grupos opositores.

A transformação na percepção da população sobre Belo Monte, pode não ser fruto de reflexão sobre impactos socioambientais, mas, como afirma um outro comerciante, um lamento pelas perdas econômicas, pois "quem ganhou dinheiro comemora e quem perde lamenta" ".

Ao mesmo tempo em que uma série de grandes obras são planejadas e implementadas na Amazônia, não se percebe uma melhora significativa nas condições de vida de suas populações. Esse fator pode ser explicado pela forma como a Amazônia é pensada pelo país, como argumenta Bermann:

"A Bacia Amazônica passou a ser identificada única e exclusivamente pelo seu potencial hidrelétrico. Estavam dadas as precondições para apropriação dos recursos naturais na Amazônia: por um lado, a disponibilidade de minérios e, por outro, os recursos hídricos monopolizados para produção de energia elétrica.” (Bermann 2012:68).

Os impactos com a construção de Belo Monte podem ser percebidos nas paisagens urbanas de Altamira e trouxeram alterações profundas e definitivas para a cidade. Assaltos, estupros, miséria, fechamento de pontos comerciais e postos de trabalho, desorganização urbana e do cotidiano das famílias são realidades que podem ser exemplificadas em conversas com moradores e reforçadas em uma análise sobre as transformações pelas quais passou a cidade. CCBM e Norte Energia comemoram os resultados alcançados e di- 
vulgam as melhorias que, segundo eles, propiciaram para as vidas de milhares de pessoas da região. $\mathrm{Na}$ lógica das compensações ou reparações para adequar as pessoas e a natureza ao empreendimento e viabilizar sua construção, os atores locais não são vistos como dotados de autonomia e direitos, mas como um meio para garantir o "desenvolvimento" nacional.

Contudo, se Belo Monte representa o fim de uma era para a cidade de Altamira, marca também o início de um novo momento. Se, inicialmente, ante o crescimento da violência, as pessoas passaram se trancar em suas casas com medo, após este momento, buscaram reinventar suas práticas de lazer e sociabilidade. O mesmo fenômeno ocorreu no tocante à moradia, pois os valores da compra e venda de imóveis vêm caindo progressivamente, permitindo que muitos saiam das ruas para passar a viver novamente em casas. Também os RUCs foram construídos ampliando a oferta de imóveis aos grupos que viviam próximo ao rio e que em um primeiro momento ficaram sem ter onde e nem como viver adequadamente com suas famílias. Cabe ressaltar, porém, que estas novas possibilidades surgidas em uma fase de declínio de mão de obra necessária para o empreendimento não devolve às condições de vida anteriores, nem repõe necessariamente os prejuízos e sim anuncia uma nova era substituindo o apocalipse que encerrou outra era.

Belo Monte precisa assim ser estudada e analisada em diversas dimensões, para possibilitar refletir sobre a Amazônia e problematizar as atuais e futu- ras obras já em discussão para garantir energia ou minérios ao país, com os recursos naturais da região. Comércio, violência, habitação, desabrigados e propagandas são um meio necessário para pensar Belo Monte e também o futuro e o presente de uma região cujos moradores falam sobre o apocalipse que transformou a cidade e a vida de milhares de pessoas.

\section{NOTAS}

${ }^{1}$ Professor do Programa de Pós-Graduação em Linguagens e Saberes da Amazônia e do Campus de Altamira da UFPA. Doutor em História pela Universidade Federal Fluminense e Mestre em Antropologia pela UFPA.

${ }^{2}$ Todos os nomes dos interlocutores, presentes neste artigo, são fictícios para preservar suas identidades.

${ }^{3}$ Os RUCs são bairros construídos pela Norte Energia, para assentar as famílias que foram desabrigadas em consequência das obras de Belo Monte.

${ }^{4}$ Informação oral feita no cais, em frente à sua casa, no dia 24 de janeiro de 2016.

${ }^{5}$ Informação verbal no dia 24 de janeiro de 2016, no cais da orla, em frente a sua canoa alagada e ancorada em frente a sua casa.

${ }^{6}$ Conversa em frente ao Xingu Hotel, Altamira, 24 de Janeiro de 2016.

${ }^{7}$ Conversa na recepção do Xingu Hotel, Altamira, 24 de Janeiro de 2016.

${ }^{8}$ Anotação do diário de campo, de diálogo com a comerciante, no centro comercial de Altamira, em 29 de março de 2016.

${ }^{9}$ Anotação do diário de campo, de diálogo com o comerciante, próximo ao Campus da UFPA/Altamira, em 21 de março de 2016. 


\section{REFERÊNCIAS}

Bermann, C. 2012. Os projetos das mega-obras hidrelétricas na Amazônia: sociedade e ambiente frente à ação governamental, in Desenvolvimento, reconbecimento de direitos e conflitos territoriais. Editado por A. Zhouri, pp. 66-97. Brasília, Associação Brasileira de Antropologia.

Block, F. 2012. Introdução, in A grande transformação, as origens de nossa época. Editado por K. Polanyi, pp.XXVII-XLVIII. Rio de Janeiro, Jorge Zahar.

Borges, A. 2015. O fim das obras dos barrageiros. O Estado de S. Paulo, 27 de jun. Disponível em http://economia.estadao.com. br/noticias/geral,nova-noticia, 1714861. Acesso em 13.04.2016.

Duarte, L. 1999. O apocalipse e a volta do Messias: a promessa de um novo céu e uma nova terra. Rio de Janeiro: Mauad. Disponível em < https://books.google.com. br/books?id=PNxpDis7O8gC\&pg $=\mathrm{PA}$ $91 \& \mathrm{dq}=\mathrm{g} \% \mathrm{C} 3 \% \mathrm{~A}$ Anero +1 iter $\% \mathrm{C} 3 \% \mathrm{~A}$ 1 rio + apocal $\%$ C $3 \%$ ADptico\&hl $=$ pt-BR \&sa $=$ X\&ved $=0 \mathrm{ahUKEwjEpbLDzuDZ}$ AhVN0VMKHTC3AMAQ6AEINiAD $\#_{\mathrm{v}}=$ onepage\&q $=\mathrm{g} \% \mathrm{C} 3 \%$ AAnero $\% 20$ $1 \mathrm{i}$ t e r $\%$ C $3 \%$ A 1 ri o $\% 20$ apocal $\% \mathrm{C} 3 \% \mathrm{ADptico} \& \mathrm{f}=$ false $>$ Acessado em 09/03/2018.

Falcão, A. 2010. Belo Monte: uma usina de conhecimento. Rio de Janeiro, Insight.

Gomes, V. 2009. Considerações técnicas sobre os indicadores propostos para mitigar os impactos da implantação do AHE Belo Monte, relativos aos serviços de infraestrutura públicos in Painel de Especialistas: análise crítica do Estudo de Impacto Ambiental do Aproveitamento Hidrelétrico de Belo Monte. Editado por S. B. Magalhães \& F. D. M. Hernandez, pp. 91-93. Belém.

Instituto Socioambiental. 2015. ISA publica dossiê "Belo Monte - Não há condições para a Licença de Operação”. Disponível em <http://www.socioambiental.org/pt-br/noticias-socioambientais/isa-publica-dossie-belo-monte-nao-ha-condicoes-para-a-licenca-de-operacao>. Acesso em 01.11.2015.

Krautler, E. 2005. Mensagem de abertura. in Tenotã-Mõ - alertas sobre as consequências dos projetos hidrelétricos no rio Xingu Editado por O. Sevá Filho, pp. 9-12. São Paulo, International Rivers Network.

Latour, B. 1994. Jamais fomos modernos. Rio de Janeiro, Editora 34.

Magalhães, S.B. \& F.D.M. Hernandez. 2011. Ciência, cientistas e democracia desfigurada: o caso Belo Monte. Novos Cadernos do NAEA 14:79-96.

MARTINS, H. 2003. Aceleração, progresso e experimentum bumano. in Dilemas da civilização tecnológica. Editado por H. Martins, J. L. Garcia, pp.19-77. Lisboa, ICS.

O aviso dos Caiapós. 1989. Revista Veja 1 de mar. (caderno Ecologia). Disponível em http://veja.abril.com.br/acervodigital/ home.aspx. Acesso em 20.02.2016.

Polanyi, K. 2012. A grande transformação, as origens de nossa época. Rio de Janeiro, Jorge Zahar.

Prudente, A.S. 2010. Hidrelétrica de Belo Monte: manifesta agressão ao princípio da proibição do retrocesso ecológico. Revista CEI 51:33-40.

Sevá Filho, O. 2005. Tenotã-Mõ - alertas sobre as consequências dos projetos hidrelétricos no rio Xingu. São Paulo, International Rivers Network.

Zhouri, A. \& R. Oliveira. 2012. Experiências locais e olhares globais: desafios para os moradores do Vale do Jequitinhonha (MG) no campo ambiental, in Cultura, percepção e ambiente, diálogos com Tim Ingold. Editado por C.A. Steil e I.C.M. Carvalho, pp.191-209. São Paulo, Terceiro Nome. 
Guerra, G. A. D. | Souza, C. M. de

Zhouri, A. 2012, Belo Monte: crise do sistema ambiental e da democracia, in Desenvolvimento, reconbecimento de direitos e conflitos territoriais. Editado por A. Zhouri, pp. 4565. Brasília, Associação Brasileira de Antropologia. 